\title{
Repurposing NASVAC, a hepatitis B therapeutic vaccine, for pre- and postexposure prophylaxis of SARS-CoV-2 infection
}

Sheikh Mohammad Fazle Akbar ( $\sim$ sheikhmohammadfazle@gmail.com )

Department of Gastroenterology and Metabology, Ehime University Graduate School of Medicine, Ehime 791-0295, Japan

\section{Mamun Al Mahtab}

Bangabandhu Sheikh Mujib Medical University, BSMMU, Dhaka 1000, Bangladesh.

\section{Julio Cesar Aguilar}

Center for Genetic Engineering and Biotechnology, Havana 10600, Cuba.

\section{Mohammad Helal Uddin}

Specialized Liver Center, Dhaka, Bangladesh

\section{Sakirul Islam Khan}

Department of Anatomy and Embryology, Ehime University Graduate School of Medicine, Ehime 791-

0295, Japan.

\section{Osamu Yoshida}

Department of Gastroenterology and Metabology, Ehime University Graduate School of Medicine, Ehime 791-0295, Japan

\section{Eduardo Penton}

Center for Genetic Engineering and Biotechnology, Havana 10600, Cuba.

\section{Guillen Nieto Gerardo}

Center for Genetic Engineering and Biotechnology, Havana 10600, Cuba.

\section{Yoichi Hiasa}

Department of Gastroenterology and Metabology, Ehime University Graduate School of Medicine, Ehime 791-0295, Japan.

\section{Research Article}

Keywords: SARS-CoV-2, Nasal vaccine, Innate immunity, Repurposing

Posted Date: April 19th, 2021

DOI: https://doi.org/10.21203/rs.3.rs-438628/v1 
License: (c) (i) This work is licensed under a Creative Commons Attribution 4.0 International License. Read Full License 


\section{Abstract}

Severe acute respiratory syndrome coronavirus 2 (SARS-CoV-2) and the subsequent coronavirus 2019 (COVID-19) have led to tens of millions of cases and millions of deaths around the world. Although more than a year has passed since the emergence of COVID-19, more waves of the pandemic, with new variants of the deadly virus, have been reported. It seems that the virus will continue to infect people for years or decades to come and thus lead to more illnesses and deaths. The experiences last year regarding limiting the transmission of the virus indicate that one or more traditional methods of containment may not be effective; further, even vaccination may not give immunity to society. On the other hand, eliminating the virus using drugs capable of eradicating SARS-CoV-2 from the infected host may not be an achievable goal. Based on these realities and after exploring the mechanism underlying the acquisition of the virus and pathogenesis of COVID-19, we assumed that immune therapy may be a practical option for the containment of SARS-CoV-2. In this study, we repurposed an immune modulator containing two antigens of hepatitis B virus, hepatitis B surface antigen (HBsAg) and hepatitis B core antigen (HBcAg) (termed NASVAC, Center for Genetic Engineering and Biotechnology, CIGB, Havana, Cuba), to gain insight into its role against SARS-CoV-2. NASVAC induced cytokines of innate immunity following nasal administration and prevented all 20 volunteers from being diagnosed with SARS-CoV-2 during the two weeks of usage. Four volunteers were infected with SARS-CoV-2 two weeks after the end of NASVAC administration; three of them showed almost no symptoms and recovered without any intervention, and one with several comorbidities attended a hospital for four days and recovered completely. In conclusion, the administration of NASVAC to subjects at risk of SARS-CoV-2 infection was safe. The pattern of cytokine responses and absence of infection or mild COVID-19 infection of the subjects involved in the study are preliminary evidence indicating that this product may prevent or suppress SARS-CoV-2 infection at the initial stages of SARS-CoV-2 acquisition and/or replication and deserve further exploratory trials to confirm the capacity of NASVAC as pre/postexposure prophylaxis or pre-emptive therapy in the context of SARS-CoV-2 infection.

\section{Introduction}

Severe acute respiratory syndrome coronavirus 2 (SARS-CoV-2), a novel positive-sense, single-stranded RNA beta-coronavirus, was first identified in humans in December 2019 [1]. The disease caused by SARSCoV-2 is termed coronavirus 2019 (COVID-19). As of today (March 31st 2021), approximately 128 million people have been infected with SARS-CoV-2, and more than 2.8 million COVID-19 patients have died. SARS-CoV-2 is basically a respiratory virus; however, the virus has the potential to infect other tissues beyond the respiratory tract and is capable of inducing complex pathological lesions in tissues other than the respiratory system [2-4]. SARS-CoV-2 is a coronavirus with nearly 30,000 base pairs, and mutations in the virus genome have been detected over the last 14 months. Some of its viral variants have already started spreading on a global scale. Studies, evidence, observations, and hypotheses indicate that SARSCoV-2 is not an eradicable virus and that human beings may have to live with this virus for years or 
decades $[5,6]$. Thus, the major challenge remains to limit the transmission of SARS-CoV-2 and the management of COVID-19 patients.

To contain the SARS-CoV-2 pandemic, attention has been given to the rapid diagnosis and isolation of SARS-CoV-2 (denoted as 3T by the World Health Organization (WHO)-Test, Tracing and Treat) [7]. Several countries have mandated usage of a mask, washing hands, gargling, avoiding crowded places, and implementing different forms of lockdowns. In the meantime, vaccines against SARS-CoV-2 have been developed, and millions of people have already been immunized. The positive effects of the vaccines are yet to surface, as only a minor percentage of the population of the world has received requisite vaccinations. Additionally, the association of vaccine-induced immunity and protection against SARSCoV-2 remains a conflicting idea due to limited protection by the vaccine to combat the emergence and re-emergence of new viral variants. To treat COVID-19, most countries have, in emergency, approved the usage of several antiviral drugs, and physicians have been using all sorts of drugs and oxygen supplementation to save the lives of COVID-19 patients. Most of these drugs, especially antiviral drugs, have been repurposed for treatment against COVID-19, as no anti-SARS-CoV-2 drug has been developed yet [8-10].

The factors related to the acquisition of SARS-CoV-2 are still elusive, and it is still confusing as to why some people have been infected with SARS-CoV-2 while others remain unaffected under the same or similar conditions. Again, some patients infected with SARS-CoV-2 are asymptomatic, whereas a major bulk of COVID-19 patients exhibit only mild or moderate symptoms [11-13]. Finally, certain patients may experience severe forms of COVID-19, and their health may decline.

In these frustrating situations about the improper understanding of the acquisition of SARS-CoV-2 and the diverse pathogenesis of COVID, new and novel approaches are warranted. It is now evident that viral factors (levels of virus, viral mutations, viral variants), weather (winter or summer), and the nature of the healthcare delivery system (strength and weakness) do not seem to be primarily accountable for the acquisition, pathogenesis, progression, and mortality of SARS-CoV-2 or COVID-19.

Available information and scientific evidence indicate that host immunity may be vital regarding the acquisition of infection by SARS-CoV-2 and pathogenesis of COVID-19. Host immunity can determine whether one will be infected with the virus and allow its replication, will be asymptomatic, develop mild to moderate disease, or progress to severe COVID-19. Supporting evidence regarding the critical roles of host immunity has become evident, as elderly people and people with compromised immunity, obese people with impaired immunity, and people with some comorbid conditions that affect host immunity are prone to be infected with SARS-CoV-2, develop severe forms of COVID-19, and experience a fatality [14-16].

As a general rule of the immune response system, innate immunity acts as the first line of defense against viral infections. This may be activated or induced by pattern-recognition receptors (PRRs) located on the plasma membranes, endosomal membranes, and cytosol for the recognition of viral components or replication intermediates known as pathogen-associated molecular patterns (PAMPs). Complex interactions among viruses, viral receptors, PRRs, and PAMPs determine the initial step of viral infection. 
Cells of the innate immune system, such as natural killer cells, natural killer T cells, neutrophils, dendritic cells, and cells of macrophage lineage, arrest viral localization or even destroy viruses, thus restricting their attachment to specific receptors and decreasing their rate of replication. Thus, proper activation of innate immunity may be one of the best approaches to block SARS-CoV-2 localization in the nasal cavity and their further pathogenesis $[17,18]$.

To overcome this initial defensive system, SARS-CoV-2 may adopt multiple evasive strategies that affect the natural surveillance system, and the virus may localize in the nasal and bronchial tissue [19-21]. Once SARS-CoV-2 enters the nasal mucosa, innate immunity, regulatory immunity, and adaptive immunity may have significant implications for deciding the nature of COVID-19 pathogenesis. This explains why elderly populations and immune-compromised persons are more prone to developing severe forms of COVID-19, as their immune systems are not capable of handling these critical events properly.

Based on these realities and due to the absence of specific drugs capable of inducing protective immunity against SARS-CoV-2 and COVID-19, several investigators have opted to use repurposed drugs [22-24].

We have been working regarding the induction of innate immunity, translation of innate immunity to adaptive immunity, and proper functioning of regulatory immunity via antigen-presenting dendritic cells using two antigens of hepatitis B virus (HBV): hepatitis B surface antigen (HBsAg) and hepatitis B core antigen ( $\mathrm{HBcAg})$ in different animal models and in humans. The resultant product of the antigen mixture is called NASVAC. NASVAC has been used in HBV transgenic mice in Japan [25], where it exhibited a highly potent antiviral effect but did not induce hepatitis or liver damage. NASVAC was also safe in normal human volunteers in a phase I trial accomplished in Cuba [26]. A phase I/II clinical trial with NASVAC in Bangladesh in patients with chronic hepatitis B also exhibited the production of cytokines of innate immunity [27]. Finally, a phase III clinical trial with NASVAC in chronic hepatitis B patients with liver damage demonstrated that NASVAC was capable of showing anti-inflammatory effects and protecting the liver from disease progression [28]. Recently, the safety and efficacy of NASVAC has been confirmed in normal individuals and patients with chronic hepatitis B in Japan [29-32].

Based on these observations, we assumed that NASVAC may induce innate immunity to block the entry and localization of SARS-CoV-2 in normal individuals. Additionally, due to its anti-inflammatory properties, NASVAC may have therapeutic efficacy in COVID-19 patients. In addition to these properties for blocking SARS-CoV-2 acquisition and the immune-mediated regulation of inflammation in COVID-19, NASVAC is a drug that can be given by the nasal route. In fact, this route is used by SARS-CoV-2 to enter the human body. This evidence led us to repurpose NASVAC for assessing its capacity to induce innate immunity and protection against SARS-CoV-2 infection.

\section{Materials And Methods}

\section{Formulation and antigens}


HeberNasvac ${ }^{\circledR}$ (NASVAC) is a liquid formulation comprising hepatitis B surface antigens (HBsAg) and the nucleocapsid (core, $\mathrm{HBcAg}$ ) of the hepatitis $B$ virus (HBV), produced by recombinant DNA technology as virus-like particles (Center for Genetic Engineering and Biotechnology, CIGB, Havana, Cuba). NASVAC contains $100 \mu \mathrm{g}$ of each antigen in a final volume of $1.0 \mathrm{~mL}$ in saline-phosphate buffer, $\mathrm{pH}$ 7.0. No other additives, preservatives, or stabilizers are included. The antigens and the formulation were produced and released under good manufacturing practice (GMP) conditions at the production facilities of the CIGB.

\section{Pilot study}

A pilot study was planned to assess the safety and immune stimulatory effect of NASVAC in the context of SARS-CoV-2 pre-exposure prophylaxis. Two studies were planned to obtain insights into the immunomodulatory role of NASVAC and NASVAC-induced protection against SARS-CoV-2. In the first part, 20 volunteers received NASVAC (three intranasal (IN) doses on days 0,7 , and 14 and 14 sublingual (SL) administrations on a daily basis for 14 days. The profile of these 20 subjects is given in Table 1 . The volunteers were healthy subjects with a high risk of SARS-CoV-2 infection due to professional (healthcare workers) or household contacts. The study was conducted after ethical approval by the Farabi General Hospital, Dhaka, Bangladesh. The study could not be registered in ICMJE-registry due to pandemic situation of the participating countries. During the selection of volunteers, patients with lung disease, pneumonia, and severe respiratory infection were excluded.

A second study was accomplished to assess the immunomodulatory capacity of NASVAC. Ten healthy volunteers were recruited, and NASVAC was administered only once through the nasal route in the supine position. All volunteers were free from any known pathological lesions, and the sample included adults of both sexes. The volunteers provided their consent to be included in the study and to assess their levels of cytokines produced in their peripheral blood mononuclear cells (PBMCs) before and after NASVAC administration.

\section{Virology, hematology and blood chemistry}

The presence of SARS-CoV-2 RNA was assessed using an automatic system and PCR kits (Roche Diagnostics, Switzerland). Clinical laboratory hematology and hemochemistry parameters (reactive Cprotein, transaminases, creatinine, glycemia and hemochemical profiles) were evaluated following hospital-validated procedures.

\section{Clinical progression}

The patients' clinical evolution (symptoms, X-ray, chest CT) was assessed following the hospital's established protocols. In addition, the protocol included a deep analysis of adverse events, in terms of type, duration, intensity, and imputability, after each immunization.

Table 1. Demographic data subjects of the pilot study to assess SARS-CoV-2 pre-exposure prophylaxis. 


\begin{tabular}{|ll|}
\hline Variables & NASVAC treated subjects \\
\hline Sample size $(\mathrm{N})$ & 20 \\
\hline Age (years) & $14-74$ \\
\hline Sex (male/female) & $14 / 6$ \\
\hline Male $(\%)$ & $14(70)$ \\
\hline Female $(\%)$ & $6(30)$ \\
\hline Racial background (\%) & Bangladeshi $(100 \%)$ \\
\hline Weight (Kg) & $45-93$ \\
\hline Height (m) & $1.46-1.77$ \\
\hline SARS-CoV-2 positivity at treatment start (\%) & 0 \\
\hline SARS-CoV-2 positivity within next 60 days (\%) & $4(25 \%)$ \\
\hline
\end{tabular}

\section{Collection of peripheral blood mononuclear cells (PBMCs)}

Blood samples were collected before and one day after the single administration of NASVAC. Peripheral blood mononuclear cells (PBMCs) were isolated and enriched by the methods previously described. Briefly, PBMCs were isolated from freshly drawn heparinized whole blood using Ficoll-Hypaque (Sigma, St. Louis, MO, USA) density gradient centrifugation. The cells were retrieved from the interface and washed three times. Finally, the PBMCs were resuspended in RPMI 1640 (Nipro, Osaka, Japan) plus 10\% autologous serum. The use of fetal calf serum (FCS) was avoided to discard the immune stimulatory effect of FCS. The viability of the PBMCs was checked by trypan blue exclusion test [33]. PBMCs ( $110^{6}$ cells $/ \mathrm{ml}$ ) were suspended, and viability was assessed. The PBMCs were cultured in the presence of lipopolysaccharides for 72 hours in an atmosphere of $95 \%$ air and $5 \% \mathrm{CO}_{2}$ under humid conditions at $37^{\circ} \mathrm{C}$ [34], and the culture supernatant was collected. The levels of cytokines in culture supernatants were measured by respective ELISA methods, exactly as per the recommendations of the manufacturer (RD Bioscience System, Minneapolis, MN, USA) [35].

\section{Statistics}

Frequency analysis was conducted using the chi-square test. For the analysis of quantitative variables in general, the groups were compared using ANOVA or the nonparametric Kruskal-Wallis test. The differences were considered statistically significant $(p<0.05)$, very significant $(p<0.01)$, or highly significant $(p<0.001)$.

\section{Results}


The assessment of NASVAC was accomplished in 20 volunteers over a period of six months. These volunteers were at the risk of being infected with SARS-CoV-2, as they were in close contact with SARSCoV-2-positive patients due to professional or household contacts. At the onset of the study, the volunteers tested negative for SARS-CoV-2, as confirmed by the PCR assessment of nasopharyngeal swabs. The volunteers were allowed to lead a normal lifestyle and normally interact with COVID-19 patients.

\section{Adverse events}

The study group received all the doses as planned, and the administration of NASVAC was safe and well tolerated. Adverse events were studied in all the participants. A total of two different adverse events were detected in four volunteers. Considering the 340 (17 doses x 20 volunteers) administered doses, $1.18 \%$ were associated with an adverse event. Local adverse events consisted of nasal drops $(2.14 \%)$ and sneezing $(0.53 \%)$. No systemic adverse event was reported. Considering the intensity of the adverse events, all of these events were mild and disappeared within minutes after onset. None of them was considered severe. No treatment was given to any of these volunteers because of adverse events.

\section{Clinical Observation}

The study was accomplished in 20 normal volunteers. The volunteers received NASVAC for 14 days. The volunteers were crucially followed up for six months and are still on the follow-up list. All the volunteers faced an increased risk of exposure to SARS-CoV-2 on a daily basis and in a random manner. None of the volunteers were infected with SARS-CoV-2 within the first 28 days or 14 days after the end of NASVAC administration. On day 30 (starting from commencement of NASVAC administration), three volunteers (serial numbers 2, 3 and 7, Table 2) tested positive for SARS-CoV-2, although they tested negative for SARS-CoV-2 when a nasal swab test was conducted before 7 days. Another person (Volunteer No 1) tested positive for SARS-CoV-2 33 days after the end of the treatment with NASVAC. Thus, a total of four out of 20 volunteers tested SARS-CoV-2 positive during the observation period. Among these, three did not develop any notable symptoms except slight cough. Only one volunteer (Volunteer No 1) was admitted to a hospital and received two liters of oxygen and symptomatic treatment. He showed no symptoms five days after being admitted to the hospital. As shown in Table 2, the patients who tested SARS-CoV-2-positive were comparatively elderly (50-75 years). In addition, all four volunteers had comorbidities. The 16 volunteers treated with NASVAC for 14 days remained negative for SARS-CoV-2 during the 6-month follow-up.

\section{Table 2. Individual profiles of the patients}




\begin{tabular}{|c|c|c|c|c|c|}
\hline Volunteers & Age (years) & $\begin{array}{l}\text { BMI } \\
\left(\mathrm{Kg} / \mathrm{m}^{2}\right)\end{array}$ & Comorbidities & SARS-CoV-2 & Treatment \\
\hline 01 & 50 & 30 & HTN, DM & (positive) & 14 days \\
\hline 02 & 50 & 24.2 & None & (positive) & 14 days \\
\hline 03 & 13 & 18.8 & None & (positive) & 14 days \\
\hline 04 & 20 & 24.6 & None & (negative) & 14 days \\
\hline 05 & 42 & 31.1 & None & (negative) & 14 days \\
\hline 06 & 43 & 28.9 & None & (negative) & 14 days \\
\hline 07 & 55 & 26.6 & HTN, DM, IHD & (positive) & 14 days \\
\hline 08 & 70 & 24.3 & HTN & (negative) & 14 days \\
\hline 09 & 71 & 20.7 & HTN, DM, IHD & (negative) & 14 days \\
\hline 10 & 65 & 26.5 & HTN & (negative) & 14 days \\
\hline 11 & 78 & 25.4 & HTN & (negative) & 14 days \\
\hline 12 & 75 & 24.6 & HTN, DM & (negative) & 14 days \\
\hline 13 & 56 & 20.7 & None & (negative) & 14 days \\
\hline 14 & 46 & 19.4 & None & (negative) & 14 days \\
\hline 15 & 48 & 20.1 & None & (negative) & 14 days \\
\hline 16 & 41 & 20.9 & None & (negative) & 14 days \\
\hline 17 & 54 & 21 & None & (negative) & 14 days \\
\hline 18 & 38 & 20 & None & (negative) & 14 days \\
\hline 19 & 26 & 20.7 & None & (negative) & 14 days \\
\hline 20 & 31 & 21.5 & None & (negative) & 14 days \\
\hline
\end{tabular}

*HTN; Hypertension; DM; Diabetic mellites, IHD; Ischemic heart disease

\section{Assessment of immune-modulatory capacity of NASVAC}

PBMCs were collected from 10 volunteers after standard nasal administration of NASVAC. These volunteers received a single NASVAC administration, and the immune modulatory capacities of these volunteers were assessed by evaluating cytokine production. PBMCs were collected from all volunteers 10 days after the administration of NASVAC. As shown in Table 3, the amount of cytokines produced by 
volunteers following NASVAC administration was significantly higher than that before the administration of NASVAC.

\section{Table 3. PBMCs' increased production of cytokines due to administration of NASVAC}

\begin{tabular}{|lll|}
\hline Cytokines in $\mathrm{pg} / \mathrm{mL}$ & Before NASVAC Administration & After Administration of NASVAC \\
\hline IFN- $\gamma$ & $160(120-240)$ & $720(260-1020)$ * \\
\hline TNF-a & $90(60-120)$ & $820(430-1020)$ * \\
\hline TGF- $\beta$ & $34(24-55)$ & $186(98-298)$ * \\
\hline IL-2 & $140(60-240)$ & $320(220-480)$ * \\
\hline IL-4 & $48(24-72)$ & $82(72-140)$ * \\
\hline IL-10 & $45(25-120)$ & $140(90-240)$ * \\
\hline
\end{tabular}

PBMCs were collected from the 10 volunteers at two points, one before the administration of NASVAC and the second one day after NASVAC administration. The cytokine production data are shown as the median with range.

\section{Discussion}

SARS-CoV-2 and COVID-19 have shattered human life as well as the economy, education, social infrastructure, normal movements, and all aspects of humane values and traditions. Approximately 128 million confirmed infections with SARS-CoV-2 (by PCR confirmation) and approximately 2.8 million deaths have occurred due to this pandemic. The emergence of SARS-CoV-2 variants is a threat to civilization. Under these realities, the prevention and propagation of SARS-CoV-2 depend on several public health measures; the implications of these measures have shown diverse effects in the global context. Recently, vaccination has started in many countries, but the outlook of the vaccination program seems to be limited due to the heterogeneous availability of vaccines, diversity about the effectiveness of different vaccines, and disinterest of a group of people to be vaccinated. In this context, all new and novel concepts regarding the prevention and management of SARS-CoV-2 and COVID-19 deserve special attention.

In this respect, we have shown that NASVAC is an immune modulatory substance that is safe and can induce innate immunity. As NASVAC is given via the nasal route, it is expected that the administration of NASVAC will induce increased levels of immunity at the nasal and oropharyngeal localities and will thus be able to counter the localization and replication of SARS-CoV-2 at the initial state. If this can be ensured about the acquisition of SARS-CoV-2 in susceptible persons, the extent of infection will decrease, and more importantly, the nature of COVID-19-related pathogenesis will become mild. This is a concept article, and we used only one regimen of NASVAC in normal volunteers; $75 \%$ of the volunteers remained SARSCoV-2 negative during an observation period of six months. More importantly, although four persons were 
infected with SARS-CoV-2, three had extremely mild diseases, and only one required hospitalization. An interesting and important observation was also made. None of the persons became infected with SARSCoV-2 during the first two weeks when they were receiving daily SL administration of NASVAC. Thus, immunization protocols may be extended to obtain preventive protection by a mechanism described as trained innate immunity [36] or be conveniently modified for direct postexposure prophylaxis/pre-emptive therapy.

For innate (nonspecific) stimulation of the immune system, NASVAC is administered via the IN and SL routes. This combination of routes optimizes Waldeyer's ring stimulation. The stimulation of mucosal immunity has been proposed as an attractive approach to confront SARS-CoV-2 and other respiratory diseases [37-38]. In particular, the stimulation of agonists of local innate immunity receptors (TLRs) involved in the detection of RNA viruses, such as TLR3 and TLR7/8, has shown a dramatic survival effect in murine models of lethal infection with SARS-CoV and influenza A virus [39, 40]. HBcAg has been described in the literature as being capable of stimulating TLR2 and TLR7 [41, 42]. In addition, HBcAg produced at CIGB has the unique capacity to stimulate TLR3 [43], activate MyD88-dependent and MyD88independent pathways, and consequently increase the expression of HLA, costimulatory molecules and interferons [43]. Simultaneous stimulation of MyD88-dependent and MyD88-independent activation pathways using commercial TLR agonists induced qualitative changes in T cell responses, which are needed for antiviral protection [44-46].

No sign of disease worsening was detected through the administration of the product or after follow-up on the developing SARS-CoV-2-positive infection. The 3 SARS-CoV-02-positive patients also had no notable symptoms. Only one patient ( 55 years and with comorbidities such as hypertension and increased $\mathrm{BMI}$ ) required a short time and noninvasive oxygen supplementation.

It has been explained that the evasion or impairment of innate sensing mechanisms or their activation pathways is a common mechanism of respiratory RNA viruses and may also justify their recurrence [47, 48]. This pilot study confirmed the immunomodulatory role of NASVAC on cytokine production by PBMCs after only one IN administration. The increased production of an array of cytokines due to stimulation with NASVAC clearly indicates its immune modulating capacity, which is consistent with previous results in CHB patients [27]. The increased production of cytokines was not associated with reactogenicity mediated by the vaccine. The effects described in the present article, taken together with the previously reported effect of NASVAC antigens on dendritic cells as well as B and T cells $[49,50]$, are attractive properties for the intended use in pre- and postexposure prophylaxis of SARS-CoV-2.

From the onset of COVID-19, drugs such as hydroxychloroquine, ivermectin, remdesivir, favipiravir, and interferon of different grades and types and some other antiviral drugs have been used for treating COVID patients. Hydroxychloroquine was originally developed for malaria, ivermectin for parasites, remdesivir for hepatitis $\mathrm{C}$ and respiratory syncytial virus, favipiravir for influenza, Ebola and Nipa virus, and interferons for nonspecific antiviral infections and cancers. Some of the drugs have been widely used 
around the world and others mostly in resource-constrained countries. However, none of these drugs could stand the test of time for the management of COVID-19.

The main causes behind the capabilities of antiviral drugs lie in the fact that the direct pathological role of the virus in COVID-19 pathogenesis may not be so dominant, and none of these antiviral drugs can eradicate SARS-CoV-2 from different organs of the body. In fact, the immune system, either incoherent immunity or cytokine storm, is fundamentally responsible for the progression of diseases due to SARSCoV-2. In this scenario, NASVAC can induce innate immunity, as evident by the production of multiple cytokines after the administration of NASVAC. Another notable factor is related to the immune regulatory capacity of NASVAC. We found that an inflammable liver with considerable levels of hepatitis in CHB patients was normalized after taking NASVAC [28].

Local stimulation by SL vaccination has been used before to prevent recurrent respiratory infections [5153]. Recently, the FDA approved the start of a phase II trial of the nasal influenza vaccine candidate TCovid (Altimmune, Gaithersburg, MD, USA), a recombinant adenovirus developed as an influenza vaccine, to be used in the setting of early SARS-CoV2 infection aimed at stimulating local innate immunity. The study was based on the capacity of the adenovirus-based influenza vaccine to prevent death in mice lethally infected with a respiratory pathogen after intranasal and not after parenteral administration [54, 55], further supporting the relevance of local and nonparenteral stimulation.

The plasmacytoid DCs, myeloid DCs, and CD14 + monocytes of COVID-19-infected individuals are less responsive to stimulation with a bacterial/viral ligand cocktail than those of healthy controls (comprising TLR-2, TLR-4 and TLR-5 ligands and TLR-3 and TLR-7/8, respectively). It is believed that the innate immune cells in the periphery of COVID-19-infected subjects have functional impairment [56, 57]. PBMCinduced production of gamma IFN and other cytokines justifies the use of NASVAC as a pre-emptive therapy or pre/postexposure prophylaxis of SARS-CoV-2 to prevent infection and to arrest the progression to severe COVID-19.

In conclusion, the present study indicates that the administration of NASVAC to subjects at risk of SARSCoV-2 infection was safe. The pattern of cytokine PBMC responses and absence of infection or mild progression of the subjects involved in the study are preliminary evidence that this product may prevent or suppress SARS-CoV-2 infection at the initial stages of replication and deserve further exploratory trials to confirm its capacity as SARS-CoV-2 pre/post exposure prophylaxis or pre-emptive therapy.

\section{Declarations}

\section{Acknowledgments:}

The study was supported in part by a grant-in-aid from the Japan Agency for Medical Research and Development (AMED) to Sheikh Mohammad Fazle Akbar (Grant number 20fk0310103h1904).

Conflict of interest: There is no potential conflict of interest about this article 


\section{References}

1. Li Q, Guan X, Wu P, Wang X, Zhou L, Tong Y, Ren R, Leung KSM, Lau EHY, Wong JY, Xing X, Xiang N, Wu Y, Li C, Chen Q, Li D, Liu T, Zhao J, Liu M, Tu W, Chen C, Jin L, Yang R, Wang Q, Zhou S, Wang R, Liu H, Luo Y, Liu Y, Shao G, Li H, Tao Z, Yang Y, Deng Z, Liu B, Ma Z, Zhang Y, Shi G, Lam TTY, Wu JT, Gao GF, Cowling BJ, Yang B, Leung GM, Feng Z. Early Transmission Dynamics in Wuhan, China, of Novel Coronavirus-Infected Pneumonia. N Engl J Med. 2020 Mar 26;382(13):1199-1207.

2. Extrapulmonary manifestations of COVID-19. Gupta A, Madhavan MV, Sehgal K, Nair N, Mahajan S, Sehrawat TS, Bikdeli B, Ahluwalia N, Ausiello JC, Wan EY, Freedberg DE, Kirtane AJ, Parikh SA, Maurer MS, Nordvig AS, Accili D, Bathon JM, Mohan S, Bauer KA, Leon MB, Krumholz HM, Uriel N, Mehra MR, Elkind MSV, Stone GW, Schwartz A, Ho DD, Bilezikian JP, Landry DW. Nat Med. 2020;26(7):1017-1032.

3. Sivaloganathan H, Ladikou EE, Chevassut T. COVID-19 mortality in patients on anticoagulants and antiplatelet agents. Br J Haematol. 2020;190(4):e192-e195.

4. Sarkesh A, Daei Sorkhabi A, Sheykhsaran E, Alinezhad F, Mohammadzadeh N, Hemmat N, Bannazadeh Baghi H. Extrapulmonary Clinical Manifestations in COVID-19 Patients. Am J Trop Med Hyg. 2020;103(5):1783-1796.

5. Wang B, Wang L, Kong X, Geng J, Xiao D, Ma C, Jiang XM, Wang PH. Long-term coexistence of SARSCoV-2 with antibody response in COVID-19 patients. J Med Virol. 2020;92(9):1684-1689.

6. Wang X, Huang K, Jiang H, Hua L, Yu W, Ding D, Wang K, Li X, Zou Z, Jin M, Xu S. Long-Term Existence of SARS-CoV-2 in COVID-19 Patients: Host Immunity, Viral Virulence, and Transmissibility. Virol Sin. 2020;35(6):793-802.

7. Griffin S. Covid-19: Test and trace programmes are important but no silver bullet, say scientists. BMJ. 2020;369:m2151.

8. Khadka S, Yuchi A, Shrestha DB, Budhathoki P, Al-Subari SMM, Ziad Alhouzani TM, Anwar Butt I. Repurposing Drugs for COVID-19: An Approach for Treatment in the Pandemic Altern Ther Health Med. 2020;26(S2):100-107.

9. Singh TU, Parida S, Lingaraju MC, Kesavan M, Kumar D, Singh RK. Drug repurposing approach to fight COVID-19. Pharmacol Rep. 2020;72(6):1479-1508.

10. Yousefi H, Mashouri L, Okpechi SC, Alahari N, Alahari SK. Repurposing existing drugs for the treatment of COVID-19/SARS-CoV-2 infection: A review describing drug mechanisms of action. Biochem Pharmacol. 2021; 183:114296.

11. Gao Z, Xu Y, Sun C, Wang X, Guo Y, Qiu S, Ma K. A systematic review of asympto-matic infections with COVID-19. J Microbiol Immunol Infect. 2021 Feb;54(1):12-16.

12. Yu X, Yang R. Influenza Other Respir Viruses. 2020;14(4):474-475.

13. Xie P, Ma W, Tang H, Liu D. Severe COVID-19: A Review of Recent Progress With a Look Toward the Future. Front Public Health. 2020;13;8:189. 
14. Hussain A, Mahawar K, Xia Z, Yang W, El-Hasani S. Obesity and mortality of COVID-19. Metaanalysis. Obes Res Clin Pract. 2020;14(4):295-300.

15. Galmés S, Serra F, Palou A. Current State of Evidence: Influence of Nutritional and Nutrigenetic Factors on Immunity in the COVID-19 Pandemic Framework. Nutrients. 2020;12(9):2738.

16. Fang X, Li S, Yu H, Wang P, Zhang Y, Chen Z, Li Y, Cheng L, Li W, Jia H, Ma X. Epidemiological, comorbidity factors with severity and prognosis of COVID-19: a systematic review and metaanalysis. Aging (Albany NY). 2020 Jul 13;12(13):12493-12503.

17. Blanco-Melo D, Nilsson-Payant BE, Liu WC, Uhl S, Hoagland D, Møller R, Jordan TX, Oishi K, Panis M, Sachs D, Wang TT, Schwartz RE, Lim JK, Albrecht RA, tenOever BR. Imbalanced Host Response to SARS-CoV-2 Drives Development of COVID-19. Cell. 2020;181(5):1036-1045.

18. Sallenave JM, Guillot L. Innate Immune Signaling and Proteolytic Pathways in the Resolution or Exacerbation of SARS-CoV-2 in Covid-19: Key Therapeutic Targets? Front Immunol. 2020 28;11:1229.

19. Bouayad A. Innate immune evasion by SARS-CoV-2: Comparison with SARS-CoV. Rev Med Virol. 2020;30(6):1-9.

20. Park MD. Immune evasion via SARS-CoV-2 ORF8 protein? Nat Rev Immunol. 2020;20(7):408.

21. Lei X, Dong X, Ma R, Wang W, Xiao X, Tian Z, Wang C, Wang Y, Li L, Ren L, Guo F, Zhao Z, Zhou Z, Xiang $Z$, Wang J. Activation and evasion of type I interferon responses by SARS-CoV-2. Nat Commun;11(1):1-2.

22. WHO Solidarity Trial Consortium, Pan H, Peto R, Henao-Restrepo AM, Preziosi MP, Sathiyamoorthy V, Abdool Karim Q, Alejandria MM, Hernández García C, Kieny MP, Malekzadeh R, Murthy S, Reddy KS, Roses Periago M, Abi Hanna P, Ader F, Al-Bader AM, Alhasawi A, Allum E, Alotaibi A, Alvarez-Moreno CA, Appadoo S, Asiri A, Aukrust P, Barratt-Due A, Bellani S, Branca M, Cappel-Porter HBC, Cerrato N, Chow TS, Como N, Eustace J, García PJ, Godbole S, Gotuzzo E, Griskevicius L, Hamra R, Hassan M, Hassany M, Hutton D, Irmansyah I, Jancoriene L, Kirwan J, Kumar S, Lennon P, Lopardo G, Lydon P, Magrini N, Maguire T, Manevska S, Manuel O, McGinty S, Medina MT, Mesa Rubio ML, MirandaMontoya MC, Nel J, Nunes EP, Perola M, Portolés A, Rasmin MR, Raza A, Rees H, Reges PPS, Rogers CA, Salami K, Salvadori MI, Sinani N, Sterne JAC, Stevanovikj M, Tacconelli E, Tikkinen KAO, Trelle S, Zaid H, Røttingen JA, Swaminathan S. Repurposed Antiviral Drugs for Covid-19 - Interim WHO Solidarity Trial Results. N Engl J Med. 2021;384(6):497-511.

23. Dube T, Ghosh A, Mishra J, Kompella UB, Panda JJ. Repurposed Drugs, Molecular Vaccines, ImmuneModulators, and Nanotherapeutics to Treat and Prevent COVID-19 Associated with SARS-CoV-2, a Deadly Nanovector. Adv Ther (Weinh). 2020; 25:2000172.

24. Owji H, Negahdaripour M, Hajighahramani N. Immunotherapeutic approaches to curtail COVID-19. Int Immunopharmacol. 2020; 88:106924.

25. Akbar SM, Chen S, Al-Mahtab M, Abe M, Hiasa Y, Onji M.. Strong and multi-antigen specific immunity by hepatitis $B$ core antigen ( $\mathrm{HBcAg}$ )-based vaccines in a murine model of chronic hepatitis $\mathrm{B}$ : $\mathrm{HBcAg}$ is a candidate for a therapeutic vaccine against hepatitis B virus. Antiviral Res. 2012;96(1):59-64. 
26. Betancourt AA, Delgado CA, Estévez ZC, Martínez JC, Ríos GV, Aureoles-Roselló SR, Zaldívar RA, Guzmán MA, Baile NF, Reyes PA, Ruano LO, Fernández AC, Lobaina-Matos Y, Fernández AD, Madrazo Al, Martínez MI, Baños ML, Alvarez NP, Baldo MD, Mestre RE, Pérez MV, Martínez ME, Escobar DA, Guanche MJ, Cáceres LM, Betancourt RS, Rando EH, Nieto GE, González VL, Rubido JC. Phase I clinical trial in healthy adults of a nasal vaccine candidate containing recombinant hepatitis $B$ surface and core antigens. Int J Infect Dis. 2007;11(5):394-401.

27. Al-Mahtab M, Akbar SM, Aguilar JC, Uddin H, Khan MS, Rahman S. Therapeutic potential of a combined hepatitis B surface antigen and core antigen vaccine in patients with chronic hepatitis $B$. Hepatol Int 2013; 7(4):981-989

28. Al Mahtab M, Akbar SMF, Aguilar JC, Guillen G, Penton E, Tuero A, Yoshida O, Hiasa Y, Onji M. Treatment of chronic hepatitis B naïve patients with a therapeutic vaccine containing $\mathrm{HBs}$ and $\mathrm{HBc}$ antigens (a randomized, open and treatment controlled phase III clinical trial). PLoS One.13(8):e0201236. (2018).

29. Yoshida O, Akbar SM, Kohara M, Kohara K, Miyazaki T, Kamishita T, Al Mahtab M, Aguilar JC, Guilen G, Hiasa Y. Induction of anti-HBs and reduction of HBs antigen by nasal administration of a therapeutic vaccine containing HBs and HBc antigen (NASVAC) in patients with chronic hepatitis B. American Association for Study of the Liver, Boston, MA, USA, November 10th 2019

30. Hiasa Y, Yoshida O, Guillen G, Aguilar JC, Kohara K, Tsukiyama-Kohara K, Miyazaki T, Kamishita T, Al Mahtab M, Akbar SM. The HB vaccine containing HBs and HBc antigen (NASVAC) can effectively induce anti-HBs antibody in non-responders to the prophylactic vaccine. American Association for Study of the Liver, Boston, MA, USA, November 10th 2019

31. Yoshida O, Imai Y, Akbar SMF, Kohara M, Kohara K, Miyzaki T, Kamishita T, Al Mahtab M, Aguilar JC, Guillen G, Hiasa Y. A nasal administrative therapeutic vaccine (NASVAC) with modified treatment strategy reduces and eliminates HBs antigen in HBV infected patients with or without nucleos(t)ide analogs therapy. The Liver Meeting, AASLD, San Francisco, USA, November 8-12, 2018

32. Yoshida O, Imai Y, Akbar SMF, Kohara M, Kohara K, Miyzaki T, Kamishita T, Al Mahtab M, Aguilar JC, Guillen G, Hiasa Y. HBsAg Reduction by Nasal Administration of A Therapeutic Vaccine Containing HBsAg and HBcAg (NASVAC) in A Patients with Chronic HBV Infection: The Results of 18 months follow-up. The Liver Meeting, AASLD, November 13-16, 2020.

33. Akbar SM, Furukawa S, Horiike N, Abe M, Hiasa Y, Onji M. Safety and immunogenecity of hepatitis B surface antigen-pulsed dendritic cells in patients with chronic hepatitis B. J Viral Hepat 2011;18:408-414.

34. Akbar SM, Furukawa S, Nakanishi S, Abe M, Horiike N, Onji M. Therapeutic efficacy and decreased nitrite production by bezafibrate in patients with primary biliary cirrhosis. J Gastroenterol 2005;40:157-163.

35. Akbar SM, Furukawa S, Onji M, Murata Y, Niya T, Kanno S, Murakami H, Horiike N. Safety and efficacy of hepatitis B surface antigen-pulsed dendritic cells in human volunteers. Hepatol Res 2004;29:136141. 
36. Sánchez-Ramón S, Conejero L, Netea MG, Sancho D, Palomares Ó, Subiza JL. Trained immunitybased vaccines: a new paradigm for the development of broad-spectrum anti-infectious formulations. Front Immunol 2018;9:2936.

37. Moreno-Fierros L, García-Silva I, Rosales-Mendoza S. Development of SARS-CoV-2 vaccines: should we focus on mucosal immunity? Expert Opin Biol Ther. 2020;20(8):831-836.

38. Mudgal R, Nehul S, Tomar S. Prospects for mucosal vaccine: shutting the door on SARS-CoV-2. Hum Vaccin Immunother. 2020;16(12):2921-2931.

39. Kumaki Y, Salazar AM, Wandersee MK, Barnard DL. Prophylactic and therapeutic intranasal administration with an immunomodulator, Hiltonol $($ Poly IC: LC), in a lethal SARS-CoV-infected BALB/c mouse model. Antivir Res 2017;139:1-2.

40. Zhao J, Wohlford-Lenane C, Zhao J, Fleming E, Lane TE, McCray PB, Perlman S. Intranasal treatment with poly (I. C) protects aged mice from lethal respiratory virus infections. J Virol 2012; 86(21), 11416-11424.

41. Cooper A, Tal G, Lider O, Shaul Y. Cytokine induction by the hepatitis B virus capsid in macrophages is facilitated by membrane heparan sulfate and involves TLR2. J Immunol. 2005;175:3165-3176.

42. Lee BO, Tucker A, Frelin L, Sallberg M, Jones J, Peters C, Hughes J, Whitacre D, Darsow B, Peterson DL, Milich DR. Interaction of the hepatitis B core antigen and the innate immune system. J Immunol. 2009;182(11):6670-81.

43. Patent application: CU 2020-0028: Priority date: 04.20 .2020 . Viral nucleoproteins and formulations thereof.

44. Bagchi A, Herrup EA, Warren HS, Trigilio J, Shin HS, Valentine C, Hellman J. MyD88-dependent and MyD88-independent pathways in synergy, priming, and tolerance between TLR agonists. J Immunol 2007;178(2):1164-1171.

45. Zhu Q, Egelston C, Gagnon S, Sui Y, Belyakov IM, Klinman DM, Berzofsky JA. Using 3 TLR ligands as a combination adjuvant induces qualitative changes in $T$ cell responses needed for antiviral protection in mice. J Clin Invest 2010;120(2):607-616.

46. Zhu Q, Egelston C, Vivekanandhan A, Uematsu S, Akira S, Klinman DM, Berzofsky JA. Toll-like receptor ligands synergize through distinct dendritic cell pathways to induce $T$ cell responses: implications for vaccines. PNAS 2008; 105(42), 16260-16265.

47. Kikkert M. Innate immune evasion by human respiratory RNA viruses. J Innate Immun 2020;12(1):420.

48. Nelemans T, Kikkert M. Viral innate immune evasion and the pathogenesis of emerging RNA virus infections. Viruses. 2019;11(10):961-984.

49. Akbar SM, Yoshida O, Chen S, Cesar AJ, Abe M, Matsuura B, Hiasa Y, Onji M. Immune modulator and antiviral potential of dendritic cells pulsed with both hepatitis B surface Ag and core antigen for treating chronic HBV infection. Antivir Ther.2010;15(6):887-95.

50. Lobaina Y, Hardtke S, Wedemeyer H, Aguilar JC, Schlaphoff V. In vitro stimulation with HBV therapeutic vaccine candidate Nasvac activates $B$ and $T$ cells from chronic hepatitis $B$ patients and 
healthy donors. Molecular Immunol 2015;63(2):320-327.

51. Muñoz-Wolf N, Rial A, Saavedra JM, Chabalgoity JA. Sublingual immunotherapy as an alternative to induce protection against acute respiratory infections. J Vis Exp. 2014;(90):e52036.

52. Lee YN, Youn HN, Kwon JH, Lee DH, Park JK, Yuk SS, Erdene-Ochir TO, Kim KT, Lee JB, Park SY, Choi IS, Song CS. Sublingual administration of Lactobacillus rhamnosus affects respiratory immune responses and facilitates protection against influenza virus infection in mice. Antivir Res. 2013;98(2):284-90.

53. Occasi F, De Castro G, Zicari AM, Indinnimeo L, Tancredi G, Duse M. Sublingual immunotherapy in children and its potential beneficial collateral effect on respiratory tract infections. Curr Med Res Opin. 2015;31(5):939-41.

54. Altimmune: Waiting For Their Next Move Against COVID-19. News article. 16.06.2020. At: https://ir.altimmune.com/investors/news-articles.

55. Altimmune Receives Award from U.S. Department of Defense to Fund Phase 1/2 Clinical Trial of TCOVID $^{\text {TM }}$ in Outpatients with Early COVID-19. Press release. 29.06.2020. At: .

56. Arunachalam PS, Wimmers F, Mok CK, Perera RA, Scott M, Hagan T, Sigal N, Feng Y, Bristow L, Tsang OT, Wagh D. Systems biological assessment of immunity to mild versus severe COVID-19 infection in humans. Science;369(6508):1210-20.

57. Yao C, Bora SA, Parimon T, Zaman T, Friedman OA, Palatinus JA, Surapaneni NS, Matusov YP, Cerro Chiang G, Kassar AG, Patel N, Green CER, Aziz AW, Suri H, Suda J, Lopez AA, Martins GA, Stripp BR, Gharib SA, Goodridge HS, Chen P. Cell-Type-Specific Immune Dysregulation in Severely III COVID-19 Patients. Cell Rep. 2021;34(1):108590.

\section{Figures}


Fig. 1. Schedule of administration of NASVAC.

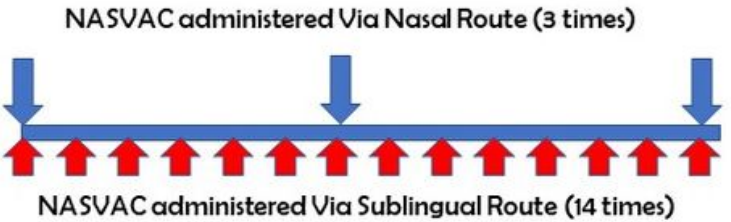

\section{Figure 1}

NASVAC administered Via Nasal Route (3 times). Schedule of administration of NASVAC. A total of 20 volunteers received three intranasal (IN) doses of NASVAC on days 0,7 , and 14 and 14 sublingual (SL) administrations on a daily basis for 14 days. 
Fig. 2. Subjects' enrollment and study design in Pilot clinical trial (Sub-study I)

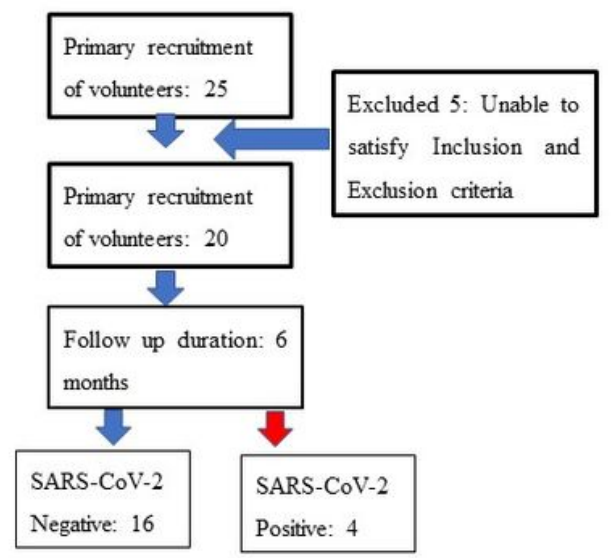

\section{Figure 2}

Subjects' enrollment and study design in the pilot clinical trial (Substudy I) 